Original @lrticles.
FOOTBALL INJURIES OF THE HARVARD
SQUAD FOR THREE YEARS UNDER THE
REVISED RULES.

EDWARD H. NICHOLS, M.D., AND FRANK L. RICHARDBON, M.D., BOBTON.

IN January, 1906 , there was published ${ }^{1}$ a report of the injuries received by the members of the Harvard University football squad while playing football during the fall of 1905 .

Before the beginning of the next football season radical changes were made in the playing rules. These changes were made partly to avoid the uninteresting " mass plays," and partly to lessen the number and severity of the injuries received in the game.

Since this revision of the rules has been made one or both of the writers of this article has been in medical charge of the Harvard football squad and has kept careful clinical records of the injuries received. At first it was the intention to make a second report at the end of the season of 1906, in order to compare the injuries received under the old rules with those received under the revised rules, but it seemed better to wait until observations could be made during a series of years in order to be able to draw more exact conclusions.

This report presents the statistics of football injuries received by members of the Harvard Varsity squad during the seasons of 1906, 1907 and 1908. All of the games during this time were played under the revised rules, which very much lessened the old-fashioned "mass plays" and made open plays much more profitable.

For the sake of comparison the statistics for the season of 1905 previously published are added. There also is included a list of the injuries received by the players of the 1906 squad previous to the season of 1906 . These latter statistics are based upon replies to a circular letter sent to the 1906 squad. The statistics of the seasons of 1906, 1907 and 1908 are based on clinical records kept during the season. The list includes all injuries which were of sufficient severity to keep men out of games or out of practice. The time during which men were kept from play is taken from the clinical records. The time during which men were out of college as a result of football injuries is taken from the records of the college office, and for these records I am indebted to Mr. George W. Cram, Recorder of Harvard College.

List of InJURIES Received By THE MEMbers of THE 1906 Squad Previous to the Season of 1906.

Fractured clavicle,

Fractured nose

Fractured finger,

Dislocated collar-bone,

Dislocated semilunar cartilage,

Dislocated finger,

Sprained shoulder,

Sprained thumb,

1 "The Physical Aspect of American Football," Nich
Smith, Boston Med."AND SURG. Jour., January, 1906, p. 1.

" . J ${ }^{2}$ Of these "sprained shoulders" it is iprobable, judging from our own experience, that some at least were partial dislocations of the outer end of the collar-bone.

\begin{tabular}{lr} 
Sprained knee, & 4 \\
Sprained ankle, & 6 \\
Contusion of the abdomen, & 1 \\
"Poop," & 2 \\
"Charley-horse," 3 & 1 \\
Concussion, & 2 \\
Tenosynovitis, & 2 \\
Multiple injuries, & 1 \\
Septic leg, & 1 \\
\multicolumn{1}{c}{ Total, } & $\frac{41}{1}$
\end{tabular}

It is to be borne in mind that the above list of diagnoses is taken from answers to a circular letter sent to the members of the $1906 \mathrm{squad}$ after the end of the season. The diagnoses are the players' own and certainly do not exaggerate the facts, as the tendency of the players is to minimize the severity and frequency of injuries.

List OF INJURIES RECEIVEd By Members OF THE HARVARD Football Squad during the Season of 1905 (Old

Rules) and Seasons of 1906, 1907 and 1908 (REvised Rules).

Diagnoses.

Fracture of cervical vertebra, of zygoma,

of nose,

clavicle,

humerus,

carpus,

metacarpus,

phalanx,

rib,

of rim of pelvis, ${ }^{4}$

fibula,

Dislocation of acromial end of clavicle,
of inner end of clavicle, of xyphoid cartilage, elbow,

shoulder, semilunar cartilage, ${ }^{5}$

Compound dislocation of finger,

Traumatic valgus,

Ruptured internal lateral ligament of knee,

" biceps of thigh, " Charley horse,"

extensor muscle of thigh, "poop,"

Synovitis of knee

Sprained elbow,

wrist,

ankle,

Injury to back, sprain,

Strained side,

Contusions,

" of side,

of side,

of elbow,

of hip,

1905. 1906. 1907. 1908

", of hip,
Cuts requiring dressings,
Crushed finger,

Crushed finger,

Hematoma of ear,

Torn ear,

Middle meningeal hemorrhage,

Concussion,

Ruptured kidney,

Septic toe

Tenosynovitis,

Totals,

$\begin{array}{rlll}1 & 0 & 0 & 0 \\ 2 & 0 & 0 & 0 \\ 7 & 2 & 1 & 1 \\ 1 & 0 & 0 & 0 \\ 0 & 0 & 1 & 0 \\ 1 & 1 & 0 & 0 \\ 3 & 0 & 0 & 1 \\ 4 & 0 & 1 & 0 \\ 5 & 0 & 1 & 0 \\ 4 & 1 & 1 & 1 \\ 1 & 1 & 1 & 0 \\ 11 & 2 & 1 & 5 \\ 1 & 0 & 0 & 0 \\ 1 & 0 & 0 & 0 \\ 1 & 0 & 0 & 0 \\ 2 & 2 & 0 & 1 \\ 0 & 0 & 0 & 1 \\ 10 & 1 & 0 & 2 \\ 2 & 0 & 0 & 0 \\ 1 & 0 & 0 & 0\end{array}$

Total number of men in squad,

3 "Charley-horse" means partial or complete rupture of one or more of the ham-string muscles of the thigh.

Verified by x-ray.
6 This does not include two dislocated semilunar cartilages

received in previous seasons.
During 1908 all players were required to wear thigh-guards, 
The last figures do not represent the entire number of men who appeared as candidates for the eleven, but represent as nearly as may be the number of men retained on the first and second squads. It is impossible to give the exact number of the men playing each day of the season, but the above figures are fairly accurate and are used as the basis in figuring percentages.

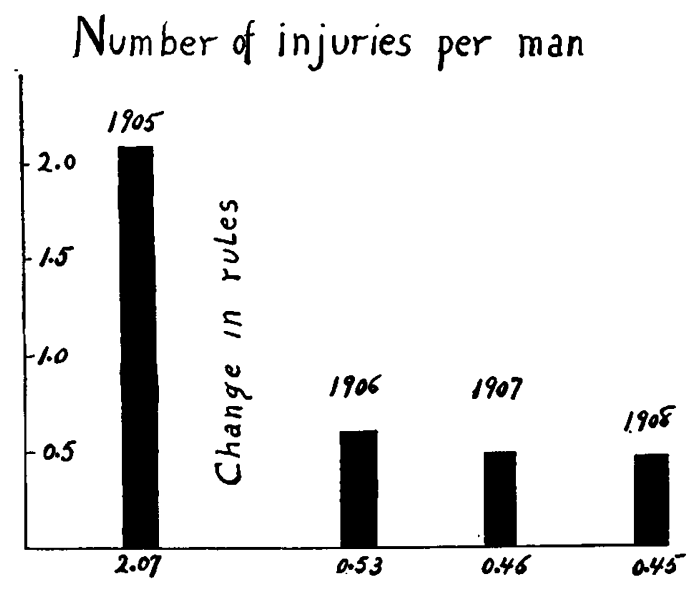

FIg. A. Graphic representation of the number of injuries per man. Vertical lines represent the average number of injuries per man.

It is interesting to see during what period of the playing season injuries are most numerous, and the figures throw some light on the cause of the injuries and the possibility of avoiding some of them.

\begin{tabular}{|c|c|c|c|c|c|c|}
\hline $\begin{array}{l}\text { Week of the } \\
\text { season. }\end{array}$ & $\begin{array}{r}1 \\
\text { Totals. }\end{array}$ & "Poops." & $\begin{array}{l}1907 \\
\text { Totals. }\end{array}$ & "Poops." & Totals. & "Poops.' \\
\hline 1 & 16 & 4 & 6 & 2 & 0 & 0 \\
\hline 2 & 3 & $\mathbf{1}$ & 10 & 2 & 0 & 0 \\
\hline$\overline{3}$ & 3 & 0 & 8 & 1 & 8 & 1 \\
\hline 4 & 2 & 0 & 6 & 0 & 5 & 0 \\
\hline 5 & 6 & 0 & 5 & 0 & 8 & 0 \\
\hline 6 & 2 & 0 & 5 & 0 & 4 & 1 \\
\hline 7 & 2 & 0 & 4 & 1 & 4 & 1 \\
\hline 8 & 0 & 0 & 1 & 1 & 3 & 0 \\
\hline 9 & - & - & - & - & 3 & 0 \\
\hline & - & 一 & - & 一 & - & - \\
\hline Totals, & 34 & 5 & 45 & 7 & 35 & 3 \\
\hline
\end{tabular}

This table shows that "poops" come most commonly in the early part of the season. The clinical records show that these early cases occur most often in heavy or fat men and that they are the result of quick starting from a crouching position before the thigh muscles are accustomed to the unusual strain. During the season of 1908 these injuries from starting were entirely avoided, partly as a result of a circular letter which gave detailed directions for a course of preliminary work for the heavy men, and partly by starting the practice very gradually.

"Poops" also may be caused by violent contact of a flexed thigh with tense muscles with some hard object, such as an opponent's head or shoulder. These injuries, of course, cannot be avoided by preliminary work.

Dislocations of the outer end of the collar bone, either partial or complete, also are common in the early part of the season and frequently are due to work in "tackling the dummy" or in "falling on the ball," although a few cases occur as the result of tackling in games. This injury is very largely an avoidable one and seldom occurs among the skilled players. It is noticeable that each year the number of injuries per week diminishes toward the end of the season. This is due to several reasons: To a survival of the fittest, to the fact that only the skilled players are left on the squad, and, moreover, especial pains are taken to avoid injury at this time of year to the first-string men.

The opinion is held that the injuries are the result of extreme competition and that they are more commonly received in games than in practice; this, we think, is not true. During the season of 1908 ten games were played, and the injuries were distributed as follows:

\begin{tabular}{ll}
\multicolumn{1}{c}{ Game. } & \multicolumn{1}{c}{ Injuries. } \\
Bowdoin, & 1 "poop." \\
Maine, & 1 "concussion." \\
Bates, & No injuries. \\
Williams, & " " \\
Springfield, " " & Navy, \\
Brown, & 3 contusions. \\
Indians, & 1 "poop." \\
Dartmouth, 3 contusions. & 1 partial dislocation of the outer end of \\
& collar-bone. \\
Yale, & A twisted knee and injury to an old shoulder
\end{tabular}

This shows that the injuries are about the same during practice as during games, and it is noticeable that the more serious injuries this year were received in practice. The severity of the injuries can be measured in some degree by the time spent at the Infirmary by injured men. The list of men from the varsity squad who have been patients at the Infirmary appears below:

$\begin{array}{lccc} & 1906 . & 1907 . & 1908 . \\ \text { Patients, } & 9 & 11 & 7 \\ \text { Days in Infirmary, } & 47 & 27 & 21\end{array}$

In 1906 one patient was in the hospital twentytwo days with a ruptured kidney, which did not come to operation. In 1907 one patient was in nine days with a ruptured lateral ligament. In 1908 one patient was in the Infirmary eleven days with a complete dislocation of the outer end of the clavicle.

Another index of the severity of the injuries is the time men are kept out of play and away from college exercises. The following table shows the total number of days men were kept out of practice or out of college:

$\begin{array}{lccrrr}\text { Year. } & \begin{array}{c}\text { Number of } \\ \text { men in } \\ \text { squad. }\end{array} & \begin{array}{c}\text { Total days } \\ \text { out of } \\ \text { play. }\end{array} & \begin{array}{c}\text { Average } \\ \text { per man. }\end{array} & \begin{array}{c}\text { Days out } \\ \text { oflege. }\end{array} & \begin{array}{r}\text { Average } \\ \text { per man. }\end{array} \\ 1905 & 70 & 1057 & 15.10 & 128 & 1.83 \\ 1906 & 64 & 445 & 6.95 & 73 & 1.14 \\ 1907 & 98 & 480 & 4.89 & 153 & 1.56 \\ 1808 & 75 & 312 & 4.16 & 60 & 0.80\end{array}$

The number of days out of college in 1907 is large but is not an accurate index of injuries of unusual severity, but merely indicates the location of the injury, as that year there was 
an unusual number of injuries to the leg which made walking difficult.

Certain injuries are common among football men which are not frequently seen elsewhere.

rnncussion of the brain has been frequent, although as a rule not severe. In 1905 no game was played in which concussion of some degree did not occur. In 1907 , four of the five cases occurred in games. One case was severe, occurring in practice, the patient being for a time entirely unconscious and confined to the Infirmary for three days. This man still complains of difficulty in studying and concentrating his mind and of almost constant headaches. In all of these cases there is some failure to recall the events of the day on which the injury occurred. This loss of recollection, reported in the previous paper, was observed to be constant in the later cases. It is noticeable that as soon as the patient recovers his senses he cannot recollect events for a variable period of time previous and subsequent to the injury. After a few days this period of lost time has diminished in both directions, but complete recollection seems not to occur.

Number of days out of play per man $\mathbb{Q}$ Number of days out of college per man

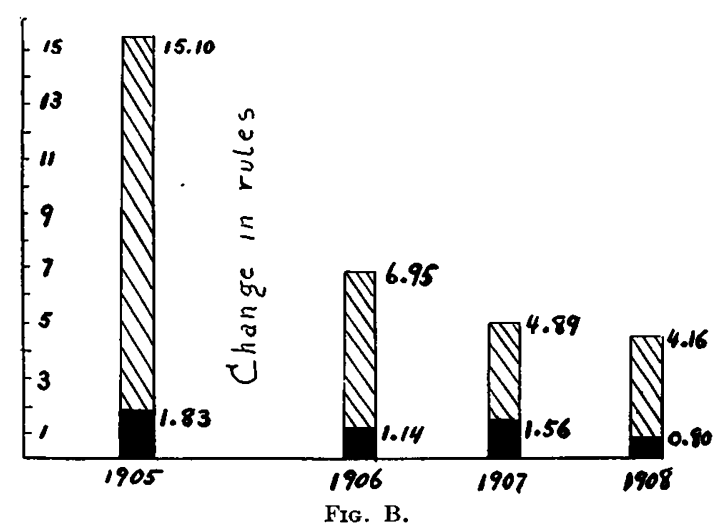

As in previous years, all cases, no matter how slight, have been sent to the Infirniary over night in order to avoid the possibility of delayed middle meningeal hemorrhage or a recurrence of excitement and delirium, as sometimes occurs. The night of admission to the hospital the patients are given a milk diet and a saline cathartic. The following morning, if perfectly clear, they are allowed to return to college.

It is curious to notice the different degrees of confusion which result from the injury. It often happens that the other players notice nothing wrong with the injured man, although from the side lines his irresponsible conduct may be evident. A mian injured in the head may continue to " line up" for a long series of plays and may automatically go through his assignments, although if questioned he may be unable to tell his name, residence, the day of the week or the name of the opposing teami. It undoubtedly is true that games have been lost by men injured in this way, so that they are quite irresponsible for their actions, without their mates recognizing that anything was wrong.

\section{DISLOCATION OF THE SEMILUNAR CARTILAGE.}

This injury is quite frequent and results in great incapacity. No player who has been injured in this way should be considered a dependable player by any coach. The injury is most commonly received by a man's being tackled below the knee and then going down in the pile, twisting his knee in the process. The cases invariably are followed by a pretty violent acute synovitis; many although not all cases show an inımediate locking of the knee-joint. The subsequent disability varies a good deal, depending apparently upon the position of the torn end of the cartilage. Some men, after such an injury, may play half a season before there is a recurrence. Other men directly after the primary injury are troubled with constantly recurring locking of the knee, in one case so frequent that a player fell down twice in coming to the field from the college yard.

The difficulties of holding the cartilage in such a position as to prevent recurring dislocations are best overcome by means of the strapping reported in the previous paper. After a considerable experience with apparatus of various sorts, and observing the results of the use of apparatus in other hands, we are strongly of the opinion that no apparatus which will enable a player to continue in the game of football is adequate. The strapping is not satisfactory but is much more efficient than any mechanical appliance.

Players who have had a typical case of this injury are very nearly useless as players ifterwards, as they never can be depended upon. The only way such men can be made dependable is by removal of the cartilage.

Opening the knee-joint is not a trivial operation, as the knee-joint is extremely susceptible to bacterial infection, and if infection occurs, it is apt to result in more or less stiffening of the joint and in some cases is dangerous to life. Many men who have semilunar cartilages are able to carry on the ordinary vocations of life without trouble but are not dependable as football players. Such cases certainly never should be advised to have the cartilage removed for the sake of playing football. If, as sometimes happens, they prefer to take the risk, the dangers of the operation should be clearly explained to them. In some cases, however, the crippling is so great as to make it necessary to open the knee-joint.

We have operated on three such cases due to football and have seen the result of the operation in one case by another surgeon. We have found the following the best method of procedure: The night previous to the operation the knee is shaved, scrubbed and boric acid ointment is carefully rubbed into the skin and a sterile dressing applied outside. The morning of the operation the knee is scrubbed on the table, 
and the most scrupulous detail of asepsis is carried out. Nobody but the operator and the assistant is allowed in the operation. A somewhat oblique incision along the inner edge of the patellar ligament is made, opening the joint. All bleeding points are clamped and checked by pressure, and no ligatures are used. The cartilage itself is removed by scissors, and unless there is considerable bleeding, nothing but those instruments are introduced into the kneejoint. The wound is closed by interrupted silk-worm gut sutures, introduced through skin, subcutaneous tissue and fascia, and the outer edge of the serous membrane, but not entering the knee-joint, so that when the stitches are tied no foreign body of any sort is left in the joint. The skin incision is closed by a subcuticular silk-worm gut suture, and then the interrupted sutures are tied outside of that. In no case have we had any infection. The leg is put up in a plaster cast, which is not split until the tenth day, when the stitches are removed. The period of convalescence varies. In one case the player was throwing the hammer, which requires very violent twisting exercises of the knee, four weeks after his operation. Most cases, however, do not have perfectly free knee motion until about six weeks. Massage is begun on the twelfth day.

\section{SYNOVITIS OF THE KNEE}

Is a frequent injury and it often is difficult in the early stages to be sure of the exact cause of the effusion. In many cases the effusion is an index of serious joint injury; in other cases it seems to result from a simple twist. In the cases of simple synovitis, in no case during the past four years has the kneejoint been fixed by plaster or on a ham splint. The knee at first is given a long hot soak and then a heavy compression "ideal" bandage is applied. This is removed at bedtime and the knee soaked again and the bandage reapplied. Baking the joint is begun the next day, and as soon as the effusion has reached its maximum, massage is begun. Most cases of simple effusion are able to begin running and in many cases practice on the tenth day. A persistence of the effusion in almost every case is an indication of serious joint trouble which may have been overlooked at first. The advantage of this method over complete fixation is very great in the way of shortening the convalescence.

$$
\text { " Poops." }
$$

This properly includes rupture of one or more of the anterior thigh muscles and should not be applied to ordinary muscle bruises. In the ordinary bruise there is the history of a blow followed by lameness, which, as a rule, is not severe, with pain on motion, with perhaps, in a few hours, a superficial ecchymosis and diffuse tenderness. The "poop," which is a real rupture of the muscle fibers, may be due to muscular action or to a direct blow upon flexed tense thigh muscles. It is characterized by very sharply localized tenderness, as sharply localized as the pain of a fractured rib. The pain on motion in many cases is extreme and increases for twenty-four or forty-eight hours. Later there may appear great swelling. The patient cannot raise his leg from the table without bending his knee. Flexion of the thigh, in a standing posture, may be impossible beyond a few degrees. This injury is a very serious one from the player's point of view, and may lead to long crippling, the average being about three weeks. In two cases we have seen marked periosteal thickening over the lower end of the femur as shown by x-ray. The ecchymosis may not appear for several days. In some cases there is marked effusion into the knee-

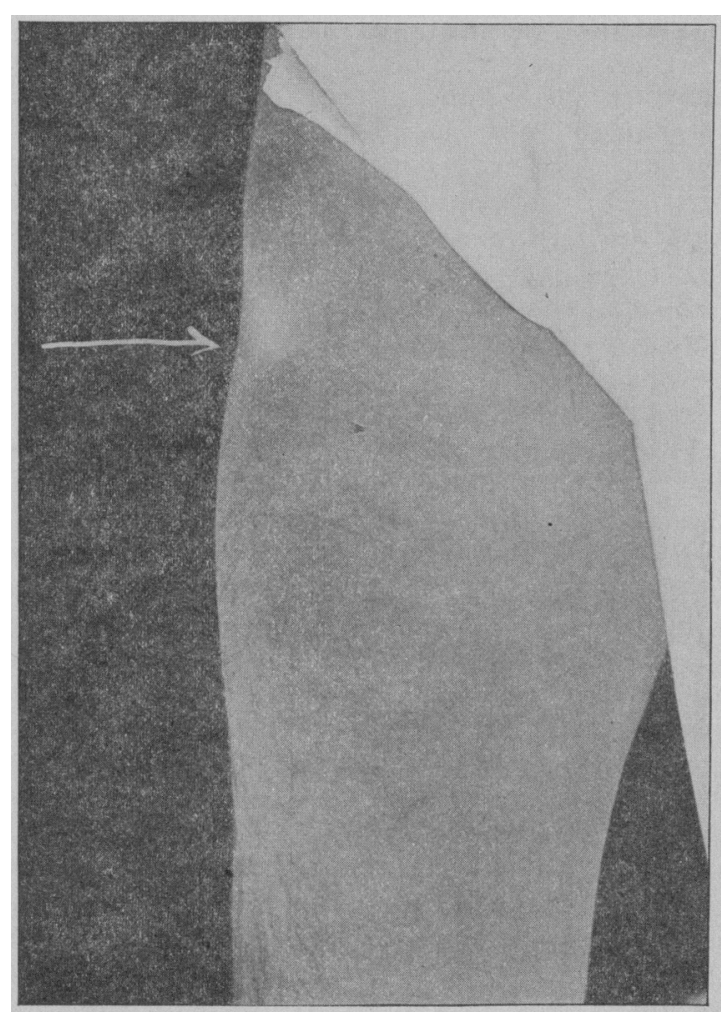

Fig. C. Photograph of net result of "poop." Injury caused by muscular action of kicking football. Photograph taken several years after injury.

joint, apparently due to an overflow of inflammatory exudation into the serous cavity. In some cases, when recovery takes place, a permanent gap is left in the belly of the muscle, and in some cases it is months before the man can properly use his leg. The best treatment is at first rest and long-continued hot soaks, aided by baking. Massage in the early stages is strongly contra-indicated. Prognosis is worse where the injury occurs to the rectus muscle. Where the injury is in the lateral thigh muscles the prognosis is much more favorable, and recovery is much more rapid. 
DISLOCATIONS OF THE OUTER END OF THE COLLARBONE.

This is a common injury, especially in the early part of the season, as has been said. The dislocation may be due to a tear of the ligaments at the outer end of the collar-bone, in which case the dislocation is only partial, although in those cases the pain and the disability may be very great. In a few cases, three during the past four years, there has been also a rupture of the coraco-clavicular ligament, leading to complete dislocation. In all three of these cases we have obtained very good cosmetic and functional results by means of the method of strapping described in the former paper. The symptoms in the cases of partial dislocation are extreme tenderness on pressure over the point between the collar-bone and the acromion, with a slight increase in the excursion of the collar-bone, in the mild cases associated with great crippling and disability in the use of the arm. In the complete cases the outer end of the collar-bone may wander around beneath the skin and lead to great disability and deformity. These injuries are extremely apt to recur, and once they have occurred demand very careful protection ever afterward; this has been carried out by means of a very heavy reinforced leather pad of special design.

PREVENTION OF INJURIES.

The players always have claimed that many of the football injuries could be avoided by skilful players. It undoubtedly is true that the skilful men are less liable to injury than the untrained ones, but no skill is sufficient to entirely prevent injuries. Many of the common injuries can be mach diminished; for instance, during the past season no "poops" due to quick starting were received. This was the result of preliminary exercise and of slow development of the men. Proper padding also prevents many of the injuries. This year, instead of leaving it to the option of the players, all men were absolutely compelled to wear proper protection, which included headgears, pads for the collar-bone and shoulders, pads over the anterior superior spines for all "backs," thigh guards, pads for the knees, and braced shoes. As a result, there were only three cases of "concussion" this year, all of slight degree. There were three "poops," one of which was received by a man who, against orders, played without his thigh guards: that is, injuries were reduced to a minimum as far as mechanical protection made it possible.

Injuries also are avoided by not playing injured men until they have entirely recovered. There is no profit in playing a cripple. The best player that ever lived, in poor condition, is not as effective as a third-string man in good condition.

Another important factor is to avoid playing men to the point of exhaustion. So long as a ch man is fresh and vigorous he is enabled to use his skill to protect himself from injury. The from that of the surgeon. minute he is completely tired and exhausted his muscles have lost their ability to protect him. This year in particular tired men have been early removed from the game and their places taken by fresh men.

An examination of the figures given above shows that there has been a marked and steady diminution in the percentage of injuries since

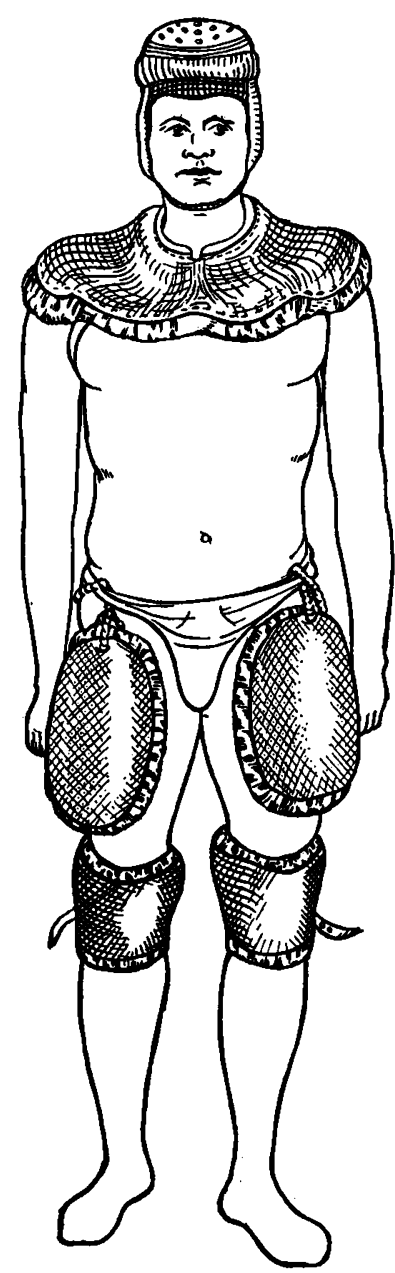

Fia. D. Protective pads used by members of the Harvard squad. Line drawing from photograph. Soft leather perforated with heavy felt, covers collar-bone and tips of shoulders. Thick with heavy felt, covers collar-bone and tips of shoulders. Thick them attached to jockey-strap for convenience in photographing really they are attached to the thigh of the football trousers. Soft leather knee pads molded to fit the knee and lined with heavy fel ting.

the revision of the football rules. All the diminution of injuries, however, is not due to the changes in the rules; some is due to the better and enforced protection of the men, to the fact that no cripples were played, and that no man was played to the point of exhaustion. Not less in importance has been the care and attention of a clever, intelligent trainer. Not only has the number of injuries been markedly diminished, but there has been a great diminution in the average of severity, and the character of the game has been changed for the better, not only from the point of view of the player and the spectator, but also 